\title{
Ainda sobre a conversibilidade
}

\author{
Still on the convertibility
}

PERSIO ARIDA*,

RESUMO: O documento introduz uma taxonomia 2x2 dos regimes cambiais em termos de restrições de conversibilidade ( $\operatorname{sim}$ ou não) e a forma de determinação de preços (taxas de câmbio flutuantes versus administradas). Argumenta-se que a conversibilidade é um sinal importante para os agentes privados. A conversibilidade livre na presença de taxas de câmbio fixas reforça a credibilidade da peg; A presença de restrições à conversibilidade frente às taxas de câmbio flutuantes revela falta de confiança do Banco Central na estabilidade do padrão monetário. O primeiro foi o caso da Argentina antes do fim do plano de Cavallo; o último é o caso do Brasil hoje. A consolidação da estabilidade monetária nas circunstâncias atuais exige um esforço fiscal sustentado; entretanto, um processo pré-anunciado de elevação gradual das restrições à conversibilidade pode, de alguma maneira, aliviar esse esforço, tornando-o politicamente viável.

PALAVRAS-CHAVE: Regimes cambiais; conversibilidade; superávit fiscal

ABSTRACT: The paper introduces a $2 \times 2$ taxonomy of exchange rate regimes in terms of convertibility restrictions (yes or no) and the form of price determination (floating versus managed exchange rates). It is argued that the convertibility is an important signal to private agents. Free convertibility in presence of fixed exchange rates reinforces the credibility of the peg; the presence of restrictions to convertibility in face of floating exchange rates reveals lack of confidence of Central Bank on the stability of the monetary standard. The former was the case of Argentina before the demise of the Cavallo plan; the latter is the case of Brazil today. The consolidation of monetary stability in present circumstances requires a sustained fiscal effort; a pre-announced process of gradual lifting of convertibility restrictions, however, may somehow alleviate such effort, thereby rendering it politically feasible. KEYWORDS: Exchange rate regimes; convertibility; fiscal surplus.

JEL Classification: F41.

Em um artigo recente, publicado no Valor em 12.11.2002, argumentei em favor da adoção de um regime de plena conversibilidade para consolidar a estabi-

\footnotetext{
* Economista. E-mail: aridap@gmail.com.

${ }^{1}$ Agradeço comentários e críticas de Edmar Bacha e André Lara-Resende.
} 
lização macroeconômica. O tripé hoje vigente de políticas (superávit fiscal primário expressivo, taxa de juros norteada pela meta inflacionária e câmbio flutuante) deveria ser aprofundado através de um programa pré-anunciado e gradual de erradicação dos controles no mercado de câmbio. Em artigo também publicado no Valor em 03.01.2003, Edmar Bacha colocou a tese na perspectiva da história do pensamento latino-americano sobre as raízes e formas de superação da fragilidade externa das nossas economias. Volto aqui ao tema, explorado desta vez sob prisma complementar e desdobrando suas relações com a questão fiscal.

$\mathrm{O}$ primeiro artigo sobre conversibilidade concentrou-se no processo de arbitragem entre juros internos e juros externos. Em regimes de conversibilidade restrita, o risco de imposição, por via administrativa, de restrições à liberdade de capitais é compensado através de uma depreciação excessiva da moeda doméstica ou de taxas de juros em reais mais altas do que deveriam ser ou ambos. Neste artigo exploro outro fator, também derivado da conversibilidade restrita, a aumentar o prêmio de risco na formação das taxas de juros internas. É que o estado de confiança nos mercados financeiros depende, em boa medida, da interpretação das políticas anunciadas pelo Banco Central. A manutenção de regimes de conversibilidade restrita mesmo com taxas de câmbio flutuantes sinaliza urbi et orbi desconfiança na moeda como reserva de valor. Como conseqüência, cresce o risco percebido e portanto o superávit fiscal primário necessário para estabilizar a moeda ao longo do tempo.

\section{OS REGIMES CAMBIAIS}

É útil organizar o pensamento sobre regimes cambiais usando a matriz 2 x 2 abaixo. A matriz apresenta uma tipologia extremamente simplificada da variedade de regimes possíveis mas serve bem para ilustrar o argumento deste artigo. ${ }^{2}$

Câmbio Administrado

$(1,1)$

$(2,1)$
Câmbio Livre

\footnotetext{
${ }^{2}$ A matriz acima apresentada deixa de lado outros aspectos dos regimes cambiais que impactam as discussões sobre conversibilidade. Um destes aspectos é a distinção entre regimes que facultam a quitação de obrigações no território nacional em moeda estrangeira e regimes que vedam tal possibilidade. O Plano Cavallo pertencia ao primeiro tipo; argumentei em meu artigo anterior que o Brasil deve manter a vedação hoje existente mesmo adotando-se a livre conversibilidade. Outros aspectos de relevo poderiam ser listados (como as formas de reconhecimento legal de cláusulas de indexação atreladas à variação da moeda estrangeira, a possibilidade de escolha de jurisdição estrangeira para discussão na corte de contratos envolvendo moeda estrangeira, etc.) mas serão aqui deixados de lado porque apenas tangenciam o objeto deste artigo.
} 
No eixo horizontal os regimes são classificados de acordo com o compromisso do Banco Central em sustentar a taxa de câmbio. Em regimes de câmbio administrado, o Banco Central se compromete a comprar ou vender os montantes que os agentes estiverem dispostos a vender ou comprar à taxa de câmbio anunciada. Sendo o preço fixo, os ajustes de oferta e demanda passam a ocorrer exclusivamente nas quantidades: o Banco Central perde reservas quando a taxa fixada está abaixo daquela que vigoraria em livre mercado e vice-versa.

Em contraste, nos regimes de flutuação o Banco Central não tem compromisso público em sustentar nenhuma taxa de câmbio. Pode, a seu critério, intervir no mercado cambial em momentos determinados, ganhando ou perdendo reservas se deseja evitar a apreciação ou depreciação excessivas da moeda doméstica, mas não tem obrigação de fazê-lo. Em regimes de livre flutuação os fluxos líquidos de capitais não impactam necessariamente as reservas porque a taxa de câmbio vigente sempre equilibra oferta e demanda por moeda estrangeira.

No eixo vertical os regimes estão dispostos de acordo com a existência ou não de restrições cambiais. Em um regime com restrições, as transações no mercado de câmbio são disciplinadas por regulação específica. A série de normas legais, tipicamente complexas em sua formulação e muitas vezes conflitantes, varia de país para país e ao longo da história de cada país. Como exemplos de regulação, temos limites quantitativos para compra e venda (incluindo limite zero para determinados agentes), exigência de aprovação administrativa para determinadas transações, regras com prioridade ou filas para remessa ou internação de moeda estrangeira, possibilidade de determinação compulsória de repatriamento, alíquotas diferenciadas de imposto dependendo do tipo de transação, etc. Uma das características essenciais dos regimes com conversibilidade restrita é a faculdade concedida ao Banco Central de alterar as normas do mercado cambial de acordo com os requisitos da política econômica.

Em contraste, em um regime de livre conversibilidade as transações no mercado de câmbio são consideradas como qualquer outro tipo de transação. Não há necessidade de autorização ou regras além daquelas vigentes para transações financeiras ou de valores mobiliários como um todo.

Exemplos destes quatro regimes e de transições entre eles podem ser encontrados na história recente. O sistema de mini-bandas de câmbio, que vigorou no Brasil de 1995 a janeiro de 1999, é um exemplo de economia $(1,1)$. O regime de conversibilidade estava regulado por um enquadramento normativo específico e havia o compromisso de o Banco Central sustentar a taxa pré-anunciada que se desvalorizava microscopicamente ao longo do tempo. Hoje o Brasil é uma economia (1,2). O Plano Cavallo na Argentina, que vigorou de 1991 a 2001, foi um exemplo de economia $(2,1)$. Havia livre conversibilidade (tanto que a lei que o instituiu foi chamada de Lei de Conversibilidade) mas a taxa era fixada por lei. Hoje a Argentina também é uma economia $(1,2)$ na qual no entanto há livre conversibilidade para a entrada de capitais. A Índia é uma economia $(1,2)$ que gradualmente evolui em direção à livre conversibilidade; o México é uma economia $(2,2)$. 


\section{O ESTADO DE CONFIANÇA}

$\mathrm{Na}$ matriz há dois regimes em que se entende facilmente a relação entre câmbio e conversibilidade. Em regimes tipo $(1,1)$, o Banco Central pode vir a ter que abandonar a âncora cambial se houver uma perda exagerada de reservas, isto é, se o nível das reservas aproximar-se perigosamente de zero ou de limites mínimos requeridos por lei. Entende-se então a adoção de formas restritas de conversibilidade, sendo as normas disciplinadoras do mercado de câmbio tratadas como um instrumento de política econômica. Em momentos de crise cambial, por exemplo, podem-se impor limites de compra de moeda estrangeira, estabelecer prioridades na remessa de divisas, isentar temporariamente de tributação não-residentes, vedar a aquisição de moeda estrangeira para finalidades consideradas especulativas, etc. Também se entende facilmente a convivência da livre conversibilidade com o câmbio flutuante em regimes tipo (2,2). Não havendo compromisso de o Banco Central sustentar uma determinada taxa de câmbio, não há perda de reservas diante de fluxos de capitais negativos e portanto não há necessidade de vedar ou limitar o desejo de compra. Mas como entender regimes $(1,2)$ ou $(2,1)$ ?

A resposta está no plano das expectativas. Vejamos inicialmente o caso de regimes $(2,1)$, câmbio administrado com conversibilidade livre. Se os agentes acreditam que a taxa anunciada terá vida curta, tem início desde logo um processo especulativo de compra de dólares antecipando o colapso que se imagina venha a ocorrer. O Banco Central precisa assim convencer os agentes que sua política é crível para evitar a perda de reservas. E como se formam as expectativas dos agentes? Em parte observando o comportamento do próprio Banco Central. A adoção de conversibilidade restrita (estratégia prudente) transmite uma mensagem implícita: em determinadas circunstâncias pode não haver reservas suficientes para sustentar o câmbio. Já a adoção da conversibilidade livre afirma em alto e bom som a confiança do Banco Central em sua política. É como se o Banco Central dissesse: tenho tanta confiança no sucesso da política que permito desde agora quem quiser comprar o quanto quiser à taxa fixa ou pré-anunciada porque sempre haverá reservas suficientes. Uma estratégia ousada (plena conversibilidade) pode ser recebida com algum ceticismo mas uma estratégia prudente tende a ser vista com descrédito. Pois se o criador não confia em sua própria criatura, por que deveria o mercado fazê-lo? É pelo mecanismo de formação de expectativas que a livre conversibilidade, ao invés de fragilizar, serviu na verdade para aumentar a credibilidade da âncora cambial em alguns capítulos da história monetária latino-americana.

É claro todos sabem que Bancos Centrais podem errar em suas previsões. Mas enquanto o erro não se materializar com clareza as expectativas tendem a refletir a determinação do Banco Central em perseguir suas políticas. O voto de confiança dos mercados, no entanto, vigora até certo ponto. Não há milagre a ser feito quando a taxa de câmbio se torna excessivamente sobrevalorizada. $\mathrm{O}$ cálculo da taxa de câmbio de equilíbrio não é fácil de ser feito com exatidão mas taxas de câmbio muito erradas, como dizia Carlos Diaz-Alejandro, são como girafas - qualquer 
um as reconhece à primeira vista. ${ }^{3}$ Quando a sobrevalorização é excessiva, a perda de reservas torna-se intolerável e mais cedo ou mais tarde o Banco Central desvaloriza a moeda, independentemente da conversibilidade ser livre ou restrita.

O ponto que me interessa aqui, no entanto, não é reprisar porque regimes de câmbio administrado entram em colapso mas sim enfatizar o papel das expectativas. Em matéria de política cambial ou monetária, a leitura do que um Banco Central faz ou deixa de fazer é um elemento fundamental da formação das expectativas do próprio mercado. O ponto é sutil mas merece atenção. O Banco Central dispõe de um volume de informações superior a qualquer agente privado e por definição é o "insider" de suas próprias decisões. Tem no entanto interesse em convencer os agentes de que suas políticas serão bem-sucedidas. Disto sabem os agentes, como também sabem da superioridade de informação do Banco Central. O resultado é assimétrico. Quando o curso das políticas do Banco Central demonstra confiança na sustentabilidade do regime cambial, os agentes podem ou não esposá-la porque não sabem se a confiança demonstrada pelo Banco Central decorre de uma avaliação isenta dos fundamentos ou de uma tentativa de convencê-los; mas se o curso das políticas sinalizar desconfiança, os agentes certamente passarão a desconfiar também.

\section{AS OBJEÇÕES À CONVERSIBILIDADE}

O sistema cambial adotado até janeiro de 1999 no Brasil era uma edição melhorada das políticas cambiais baseadas em taxas de câmbio fixas ou pré-anunciadas mas, como os outros, entrou em colapso quando a girafa entrou na paisagem. Desde então temos um regime tipo $(1,2)$, câmbio livre com conversibilidade restrita. Por que não evoluímos para um regime $(2,2)$ ? Compreende-se a prudência nos estágios iniciais de implantação do câmbio flutuante mas, passados quatro anos, a pergunta se impõe porque o custo da parafernália de restrições é pago aqui e agora, na forma de taxas de juros internas mais elevadas do que o necessário ou de uma moeda excessivamente depreciada.

Há dois argumentos para não se adotar a livre conversibilidade. O primeiro é que precisaríamos de controles no mercado de câmbio para coibir os exageros de mercado. $\mathrm{O}$ argumento parte de uma premissa correta - mercados exageram mas equivoca-se na conclusão. É verdade que a taxa de câmbio não é um preço como qualquer outro e que o livre jogo da oferta e demanda por moeda estrangeira não gera necessariamente o melhor equilíbrio alocativo do ponto de vista inter-temporal. Distorções decorrentes de assimetria de informação, comportamento de "manada" ou bolhas especulativas, para não mencionar extrapolações indevidas de eventos tópicos ou transitórios, podem tipificar o mercado em vários momentos. Controles cambiais, no entanto, não são a resposta microeconômica correta para

\footnotetext{
${ }^{3}$ Carlos F. Díaz-Alejandro "Good-bye financial repression, hello financial crash”, Journal of Development Economics, 19(1/2), 1985.
} 
aplainar a volatilidade excessiva na taxa de câmbio. ${ }^{4}$ No contexto de taxas flutuantes de câmbio, Bancos Centrais sempre podem evitar a apreciação ou depreciação exageradas através da intervenção aberta, aumentando ou diminuindo suas reservas; alternativamente, podem impor taxação temporária com alíquota uniforme e universal para entrada ou saída de moeda estrangeira. Qualquer dos dois métodos é preferível a deturpar o funcionamento do sistema de preços através de normas e regulamentos que privilegiam, por ato do Príncipe, certas categorias de transação e certos agentes em detrimento dos demais.

O segundo argumento é o receio da desvalorização. Haveria uma demanda reprimida por moeda estrangeira que, se liberada, provocaria forte depreciação, complicando por conseqüência a estabilidade dos preços. Ora, isto ocorreria se, por hipótese, o câmbio estivesse abaixo do equilíbrio antes da liberalização da conta de capitais. Caso contrário, por que alguém compraria algo acima do preço que pensa que tal coisa vale? Nosso mercado de câmbio, no entanto, já tem hoje densidade suficiente de transações para refletir a média ponderada das opiniões dos agentes sobre o preço correto a cada momento do tempo. É impossível prever com exatidão a evolução da taxa de câmbio mas é certo afirmar que a taxa de câmbio de mercado reflete o preço de equilíbrio qualquer que seja o estado das expectativas sobre o futuro.

Chegamos aqui ao nó da questão. O verdadeiro argumento em prol da conversibilidade restrita em regimes com câmbio flutuante é que haveria uma demanda reprimida por moeda estrangeira mesmo a uma taxa de câmbio excessivamente depreciada. A razão é que a moeda nacional seria percebida como sendo de segunda classe. É risco de crédito em reais (ou, simplificadamente, o risco de não pagamento dos títulos da dívida pública interna) que faria com que residentes, hoje impedidos ou inibidos de comprar moeda estrangeira pela parafernália de controles, se dispusessem a pagar um preço distorcido na conversão de parte de sua riqueza financeira em moeda estrangeira se lhes fosse concedida liberdade para alocar seus recursos. ${ }^{5}$

\section{TAXA DE JUROS E FUNDAMENTOS}

É este argumento - a moeda nacional ainda seria de segunda classe — que lastreia as objeções quanto a um regime de plena conversibilidade. A percepção

\footnotetext{
${ }^{4}$ Note-se nesta conexão que volatilidade em si mesma não é necessariamente ruim do ponto de vista da alocação de recursos. Novas informações e modos de pensar afetam a cada minuto os riscos percebidos e por tabela o valor dos ativos. Porque deveria ser diferente? A maior parte dos desajustes macroeconômicos deriva não da volatilidade inerente ao mercado mas sim das tentativas de reduzi-la artificialmente. $\mathrm{O}$ endividamento privado em dólares no Brasil, por exemplo, foi induzido pela redução artificial de volatilidade da taxa de câmbio no período 1995-1999.

${ }^{5} \mathrm{O}$ risco de crédito relevante ao argumento não tem nada a ver com o risco país: é o risco do Tesouro Nacional não honrar, por qualquer motivo, suas obrigações em reais com residentes. Tal risco, por sua vez, refletiria tanto uma avaliação técnica da capacidade econômico-financeira do Tesouro quanto uma avaliação política da propensão dos governantes a honrar compromissos.
} 
negativa dos agentes, manifestada através de prêmios de risco elevados, corresponderia a uma apreensão correta da situação atual e qualquer tentativa do Banco Central de revertê-la seria vista com descrédito. O Tesouro precisaria ter acesso privilegiado ao mercado doméstico para rolar seu endividamento; padeceria de uma crise de liquidez (ou de solvência) se não pudesse contar com o mercado doméstico cativo criado pelas restrições no mercado cambial.

$\mathrm{Na}$ visão dos céticos, o Banco Central estaria sendo responsável e prudente ao manter formas restritas de conversibilidade mesmo em um regime de livre flutuação.

A conversibilidade irrestrita seria prematura porque ainda não teríamos uma política fiscal de longo prazo que pudesse garantir, de forma permanente, a estabilidade da moeda. Na visão dos céticos, a livre conversibilidade poderia ser um coroamento da estabilização fiscal, jamais um componente, ainda que parcial, da solução das nossas questões.

O contra-argumento em favor da livre conversibilidade é que a prudência excessiva nos põe em um círculo vicioso. Em matéria monetária ou cambial, o estado de confiança do mercado é influenciado pela leitura do que o Banco Central faz ou deixa de fazer. Tome-se como exemplo a forma das intervenções no mercado de câmbio. Intervenções podem ocorrer na forma convencional (venda de dólares e conseqüente diminuição de reservas) ou através do dólar referenciado (venda de papéis cambiais ou derivativos, quitáveis à taxa futura de câmbio em reais, mas não em dólares). Mas por que o Banco Central venderia um dólar referenciado ao invés de um dólar de verdade? Se o mercado é livre, poupar reservas não faz sentido algum; compra-se amanhã com tanta facilidade quanto se vende hoje, tudo sendo uma questão de julgar se a taxa de câmbio vai subir ou cair. Quando o Banco Central prefere poupar reservas, está implicitamente revelando que o valor atribuído ao dólar de verdade, depositado em NY, excede, a seus olhos, o valor da taxa de câmbio pela qual as obrigações em reais são quitadas. Comporta-se hoje tal qual imagina que os residentes viriam a se comportar se houvesse conversibilidade livre na conta de capitais.

No Brasil de hoje tanto o que o Banco Central faz (intervenções através do dólar referenciado) quanto o que deixa de fazer (ao manter o regime de conversibilidade restrita) revelam desconfiança quanto ao padrão monetário doméstico como reserva de valor. Os elevados prêmios de risco, interpretados pelo Banco Central como resultantes de avaliação exógena do mercado sobre os fundamentos e justificadores portanto de sua prudência, em boa medida apenas refletem a leitura do que ele, Banco Central, está sinalizando ao próprio mercado. O espelhamento é análogo ao que ocorre em outras dimensões da prática de Bancos Centrais. ${ }^{6} \mathrm{O}$

\footnotetext{
${ }^{6}$ Preços dos ativos, por exemplo, refletem a expectativa dos mercados sobre a taxa de juros. Bancos Centrais muitas vezes tendem a confirmar nas decisões do Comitê de Política Monetária taxas de juros que o mercado já havia embutido nos preços dos ativos. Ora, embora evitar surpresas e traumas nos mercados seja em si mesmo um fim legítimo, seguir as expectativas de mercado sistematicamente tende a produzir uma política monetária pobre. Ao confirmar as expectativas de mercado, o Banco Central pode cair na armadilha de inferir pela observação dos mercados o que ele deve fazer enquanto na
} 
círculo vicioso faz com que os prêmios de risco permaneçam elevados e suba por conseqüência o superávit primário necessário para estabilizar a moeda. Dito de outra forma: a estabilização com conversibilidade restrita exige um superávit fiscal maior do que o necessário sob livre conversibilidade.

A liberdade na conta de capitais, diga-se uma vez mais, não é uma panacéia ou um substituto para as reformas. Sua implementação deve ser gradual e observar a evolução tanto de indicadores econômicos quanto de formas institucionais, dentre as quais a independência do Banco Central. ${ }^{7}$ Seu sucesso depende da boa gestão da política econômica como um todo e, em particular, do talento e capacidade analítica de seus executores; tal qual qualquer outra proposição isolada, faz mais sentido em determinados contextos do que em outros. Dito isto, deve ser posta na agenda desde agora. Pois há duas maneiras de escapar do círculo vicioso em que nos encontramos. A primeira é sair na força bruta, por assim dizer, dependendo apenas do esforço fiscal e das reformas. A segunda é acoplar a conversibilidade a estes dois ingredientes em uma estratégia concertada de redução do custo do capital no Brasil. As duas estratégias são em princípio possíveis; implícito em meu argumento nestes dois artigos está uma avaliação de que a segunda estratégia é mais factível nas nossas condições do que a primeira e que os riscos de sua implementação são inferiores aos ganhos que poderia trazer ao País.

verdade os mercados estão apenas refletindo o que eles acham que o Banco Central pode vir a fazer. Vejase a análise de Alan Blinder (1999) Bancos Centrais: Teoria e Prática, Editora 34.

${ }^{7}$ A estabilização da moeda requer ir além da obtenção de superávits fiscais primários por um período suficientemente longo de tempo. Importa também rever as formas pelos quais fabrica-se déficits que, na linguagem da contabilidade do setor privado, não transitam por lucros e perdas e são lançados diretamente contra o patrimônio, como é o caso dos esqueletos velhos e novos (previdência, bancos públicos, estados, etc). Daí a importância das reformas institucionais. 